\title{
Sensitive quantification of BB-22 and its metabolite BB-22 3-carboxyindole, and characterization of new metabolites in authentic urine and/or serum specimens obtained from three individuals by LC-QTRAP-MS/MS and high-resolution LC-Orbitrap-MS/MS
}

\author{
Kayoko Minakata ${ }^{1}$ Koutaro Hasegawa ${ }^{1}$. Hideki Nozawa ${ }^{1}$ - Itaru Yamagishi ${ }^{1} \cdot$ Takeji Saitoh $^{2}$. Atsuto Yoshino ${ }^{2}$. \\ Masako Suzuki ${ }^{3} \cdot$ Takuya Kitamoto $^{3} \cdot$ Osamu Suzuki $^{1} \cdot$ Kanako Watanabe $^{1}$
}

Received: 2 September 2018 / Accepted: 3 October 2018 / Published online: 16 October 2018

(c) The Author(s) 2018

\begin{abstract}
Purpose A synthetic cannabinoid BB-22 and its metabolite BB-22 3-carboxyindole have not yet been quantified in human urine. The aim of this study is to establish a sensitive analytical method for the quantification of BB-22 and its 3-carboxyindole in human serum and urine specimens, and the characterization of the unreported metabolites of BB-22 in authentic urine specimens from three individuals.

Methods These compounds were extracted from $\beta$-glucuronide-hydrolyzed and unhydrolyzed urine and/or serum via liquidliquid extraction. The identification and quantification were performed using liquid chromatography (LC)-QTRAP-tandem mass spectrometry (MS/MS) and the characterization of the new metabolites was made by high-resolution LC-MS/MS.

Results The limits of detection of BB-22 and BB-22 3-carboxyindole were 3 and $30 \mathrm{pg} / \mathrm{mL}$ in urine, respectively. The devised method was applied to quantify these compounds in authentic serum and urine obtained from two drug abusers and in urine from one drug abuser. The serum levels of BB-22 were 149 and $6680 \mathrm{pg} / \mathrm{mL}$, and those of BB-22 3-carboxyindole were 0.755 and $38.0 \mathrm{ng} / \mathrm{mL}$ in cases 1 and 2, respectively. The urine levels of BB-22 were 5.64, 5.52 and $6.92 \mathrm{pg} / \mathrm{mL}$ and those of BB-22 3-carboxyindole were $0.131,21.4$ and $5.15 \mathrm{ng} / \mathrm{mL}$ in cases 1,2 and 3, respectively. New monohydroxyl metabolites retaining the structure of $\mathrm{BB}-22$ were found in the urine specimens.

Conclusions The synthetic cannabinoid BB-22 and its metabolite BB-22 3-carboxyindole were identified and quantified in authentic human serum and urine specimens for the first time, and new metabolites of BB-22 were tentatively identified in authentic urine specimens obtained from three drug users in this study.
\end{abstract}

Keywords BB-22 $\cdot$ BB-22 3-carboxyindole $\cdot$ In vivo metabolites in human urine $\cdot$ QTRAP mass spectrometry $\cdot$ Highresolution mass spectrometry $\cdot$ Authentic serum and urine specimens

\section{Introduction}

Kayoko Minakata

kminakat@hama-med.ac.jp

1 Department of Legal Medicine, Hamamatsu University School of Medicine, 1-20-1 Handayama, Higashi-ku, Hamamatsu 431-3192, Japan

2 Department of Emergency and Disaster Medicine, Hamamatsu University School of Medicine, 1-20-1 Handayama, Higashi-ku, Hamamatsu 431-3192, Japan

3 Advanced Research Facilities and Services, Hamamatsu University School of Medicine, 1-20-1 Handayama, Higashi-ku, Hamamatsu 431-3192, Japan
A psychotropic synthetic cannabinoid (SC) BB-22 [quinolin-8-yl 1-(cyclohexylmethyl)-1 $H$-indole-3-carboxylate], shown in Fig. 1, was firstly identified in herbal-type illegal products in 2013 [1]. The first generation SC, JWH-018, was active toward the $\mathrm{CB}_{1}$ receptor having an affinity 4.5 times higher than that of $\Delta^{9}$-tetrahydrocannabinol contained naturally in Cannabis sativa, while the affinity of BB-22 was reported to be about 30 times higher than that of JWH-018 [2]. As to the concentrations of BB-22 in any authentic human specimens, one study reported on its plasma level, $97 \mathrm{pg} / \mathrm{mL}$, based on liquid chromatography 


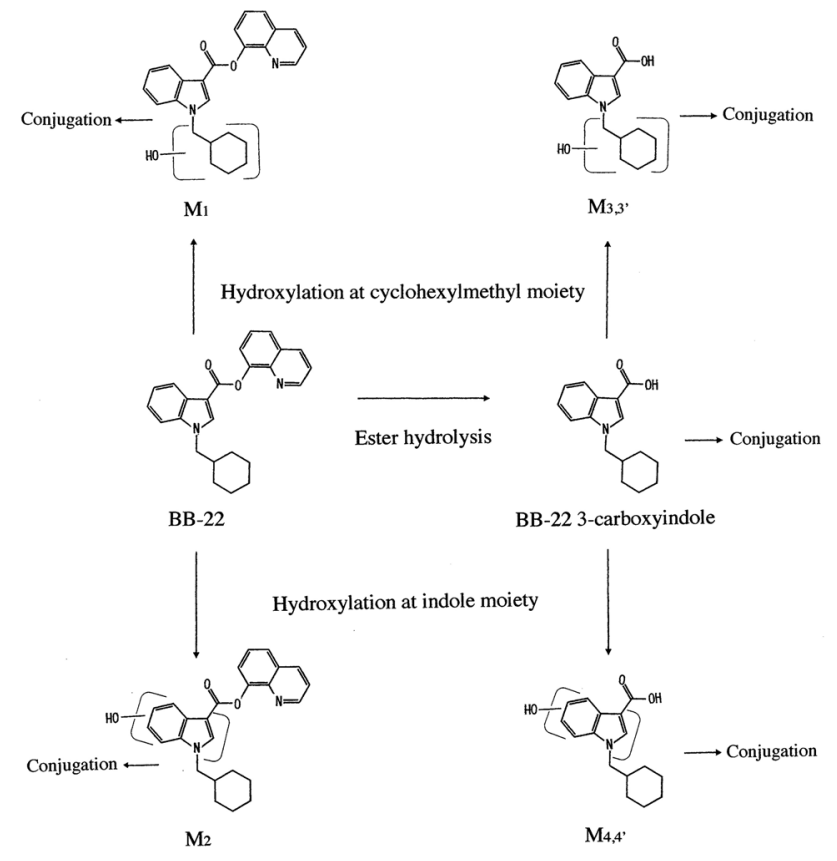

Fig. 1 Structures of BB-22, its metabolites BB-22 3-carboxyindole and metabolites M1-M4,4' showing their metabolic pathways

(LC)-mass spectrometry (MS) in 2015 [3], but its urine level has not yet been reported. BB-22 3-carboxyindole [1-cyclohexylmethyl-1 $H$-indole-3-carboxylate] and its hydroxylated metabolites (M3,3' and M4,4'), shown in Fig. 1, were reported to be produced after in vitro hydrolysis by carboxylesterases [4] and after hepatocyte in vitro metabolization [5]. However, these metabolites were also produced from MDMB-CHMICA and ADB-CHMICA [5]. The other metabolites retaining the structure of BB-22 have not been identified yet, even via in vitro study.

In the present study, BB-22 and BB-22 3-carboxyindole in authentic human urine specimens have been quantified for the first time by a sensitive LC-QTRAP tandem mass spectrometry (MS/MS) technique that was used almost in the same way for 5F-PB-22 and other six SCs in human urine specimens $[6,7]$ and 5 F-NNEI in human serum and urine specimens [8]. The present serum and urine specimens were obtained from two living patients presenting to emergency department of our university, and a urine specimen from one individual who was suspected by the police of having used illegal drugs. Although these specimens were collected in 2013, we could not identify the SC at that time mainly due to minute amounts of the $\mathrm{SC}$ in the unchanged forms and lower sensitivity of the conventional LC-MS/MS instrument used at that time. The new metabolites of BB-22 after monohydroxylation (M1 and M2 shown in Fig. 1) and metabolites after ester hydrolysis with monohydroxylation (M3,3' and M4, $4^{\prime}$ ) were tentatively identified in urine specimens using
LC-QTRAP-MS/MS and high-resolution LC-Orbitrap-MS/ MS.

\section{Materials and methods}

\section{Materials}

BB-22, BB-22 3-carboxyindole and AB-PINACA were obtained from Cayman Chemical (Ann Arbor, MI, USA); $\beta$-glucuronidase-type-H-1 from Sigma (St. Louis, MO, USA); methanol and acetonitrile suitable for LC-MS, 1-chlorobutane $(\mathrm{CB})$ suitable for amino acid analysis and other chemicals of analytical grade from Wako Pure Chemical Industries (Osaka, Japan). Pure water with a specific resistance of $18 \mathrm{M} \Omega \mathrm{cm}$ was used (Millipore, Bedford, MA, USA).

Serum and urine specimens from healthy subjects, under their permission with informed consent, were used as blank samples, and those spiked with several amounts of BB-22 and BB-22 3-carboxyindole were used as quality control samples. The authentic serum and urine specimens in all three cases were stored at $-80^{\circ} \mathrm{C}$ until analyses.

\section{Cases}

In cases 1 and 2, serum and urine specimens were collected from two patients at the emergency department of our university hospital in July 2013. In case 3, the urine specimen was collected by police in August 2013.

\section{Standard solutions}

Individual stock solutions of BB-22 and BB-22 3-carboxyindole were prepared separately by dissolving appropriate amounts of each compound in acetonitrile at $0.1 \mathrm{mg} / \mathrm{mL}$ and stored at $-30{ }^{\circ} \mathrm{C}$. Working calibration solutions and quality control solutions were prepared daily by diluting the stock solutions with blank serum or urine at $5 \mathrm{pg}-20 \mathrm{ng} / \mathrm{mL}$. ABPINACA at $1 \mathrm{ng} / \mathrm{mL}$ in serum or urine was used as internal standard (IS) for the quantification of BB-22 and BB-22 3-carboxyindole.

\section{Pretreatment}

The hydrolysis and extraction procedures were described in our previous studies for urine [6-8]. In the case of serum, a $100-\mu \mathrm{L}$ aliquot of sample was added with two stainless beads (3-mm diameter) and $300 \mu \mathrm{L}$ of $0.1 \mathrm{M}$ acetate buffer (pH 5). Here, $25 \mu \mathrm{L}$ of $\beta$-glucuronidase solution (type $\mathrm{H}-1$, 25,000 unit) was added and incubated at $37{ }^{\circ} \mathrm{C}$ for $2 \mathrm{~h}$ in 
the case of a $\beta$-glucuronide-hydrolyzed sample; this step was skipped in the case of the unhydrolyzed sample. To the sample, $1 \mu \mathrm{L}$ of $100 \mathrm{pg}$ AB-PINACA as IS and $750 \mu \mathrm{L}$ of $\mathrm{CB}$ were added, and vortexed for $30 \mathrm{~s}$. Then $40 \mathrm{mg}$ of $\mathrm{CH}_{3} \mathrm{COONa}$ and $160 \mathrm{mg}$ of $\mathrm{MgSO}_{4}$ were added, further vortexed for $90 \mathrm{~s}$, and then centrifuged at 10,000 $\mathrm{g}$ for $4 \mathrm{~min}$. The upper CB layer was transferred to a new tube. To the aqueous layer, $650 \mu \mathrm{L}$ of $\mathrm{CB}$ was added again, vortexed for $60 \mathrm{~s}$ and centrifuged at 10,000 $\mathrm{g}$ for $4 \mathrm{~min}$, and the CB layer was collected. The combined $\mathrm{CB}$ layer was evaporated to near-dryness at room temperature using a centrifugal dryer (miVac Duo LV; Genevac Ltd, Ipswich, England). The residue was reconstituted in $100 \mu \mathrm{L}$ of methanol, and centrifuged at 10,000 $g$ for $60 \mathrm{~s}$. The supernatant was used for the analysis by LC-MS/MS.

\section{Instrumental conditions}

LC-MS/MS was performed on a 4000 QTRAP MS/MS system (AB SCIEX, Framingham, MA, USA) in the positive ion mode. LC was performed using an Acquity instrument (Waters, Milford, MA, USA). A filter named SUMIPAX Filter PG-ODS (Sumika Chemical Analysis Service, Osaka, Japan) was attached before LC separation. The LC column for the chromatographic separation was TSK-GEL ODS$100 \mathrm{~V}(150 \times 2.0 \mathrm{~mm}$ i.d., particle size $5 \mu \mathrm{m}$; Tosoh, Tokyo, Japan). The mobile phase consisting of 35\% B (i.e., 65\% A) was set at a flow-rate of $200 \mu \mathrm{L} / \mathrm{min}$ for $2 \mathrm{~min}$ and then gradient elution was performed using 35-65\% B over $10 \mathrm{~min}$, switched to $100 \% \mathrm{~B}$, held for $2 \mathrm{~min}$, and returned to initial conditions over $8 \mathrm{~min}$, where solvent A was pure water containing $0.1 \%$ formic acid and $10 \mathrm{mM}$ ammonium acetate, and solvent B was $100 \%$ methanol. The MS/MS conditions were: ion source temperature, $700{ }^{\circ} \mathrm{C}$; spray needle voltage, $+5.5 \mathrm{kV}$; sheath gas pressures, 30 units for gas 1 and 50 units for gas 2; curtain gas flow, 50 units. The tandem MS collision energies and ion transitions were: $21 \mathrm{eV}$ and $\mathrm{m} / \mathrm{z}$ $385 \rightarrow 214$ for BB-22, $29 \mathrm{eV}$ and $m / z, 258 \rightarrow 118$ for BB-22 3 -carboxyindole, and $35 \mathrm{eV}$ and $\mathrm{m} / z 331 \rightarrow 215$ for AB-PINACA (IS), respectively. A 5- $\mu \mathrm{L}$ aliquot of the final extract solution was injected into the LC-MS/MS instrument.

LC-high-resolution-MS/MS was performed on an Ulti Mate 3000 coupled to a Thermo Scientific QExactive (quadrupole-Orbitrap) mass spectrometer (Thermo Scientific, Waltham, MA, USA). Chromatographic separation was achieved with the same column and the same solvent conditions as described above for LC-MS/MS performed on a 4000 QTRAP MS/MS system. The QExactive mass spectrometer was operated in positive ionization mode. The MS or MS/MS conditions were: spray voltage, $3.5 \mathrm{kV}$; capillary temperature, $250{ }^{\circ} \mathrm{C}$; heater temperature, $350{ }^{\circ} \mathrm{C}$; sheath gas, flow rate 50 units and auxiliary gas, flow rate 15 units. Nitrogen was used for the collision-induced dissociation experiment. The instrument was calibrated every $24 \mathrm{~h}$. The full MS resolution was 70,000 with scan range of $\mathrm{m} / \mathrm{z}$ 220-2000 and MS/MS resolution was 17,500 with scan range of $m / z 50-2000$. A 5- $\mu \mathrm{L}$ aliquot of the final extract solution was injected into the instrument.

\section{Results and discussion}

\section{Selected reaction monitoring chromatograms and product ion spectra}

The selected reaction monitoring (SRM) chromatograms by LC-MS/MS are shown for the detection of BB-22 (Fig. 2a), where the extract from blank urine spiked with the reference standard at $1.0 \mathrm{ng} / \mathrm{mL}$, the extract from serum in case 2 , the extract from $\beta$-glucuronide-hydrolyzed urine in case 2 , the extract from blank urine and the extract from blank urine spiked with IS at $1.0 \mathrm{ng} / \mathrm{mL}$ are shown from the top to the bottom. The equivalent SRM chromatograms are also shown for BB-22 3-carboxyindole (Fig. 2b), for the blank urine spiked with the reference standard at $10 \mathrm{ng} / \mathrm{mL}$, the serum in case $2, \beta$-glucuronide-hydrolyzed urine in case 2 , blank urine and the blank urine spiked with IS at $1.0 \mathrm{ng} / \mathrm{mL}$. Each protonated molecular ion was used as the precursor ion for acquisition of SRM chromatograms.
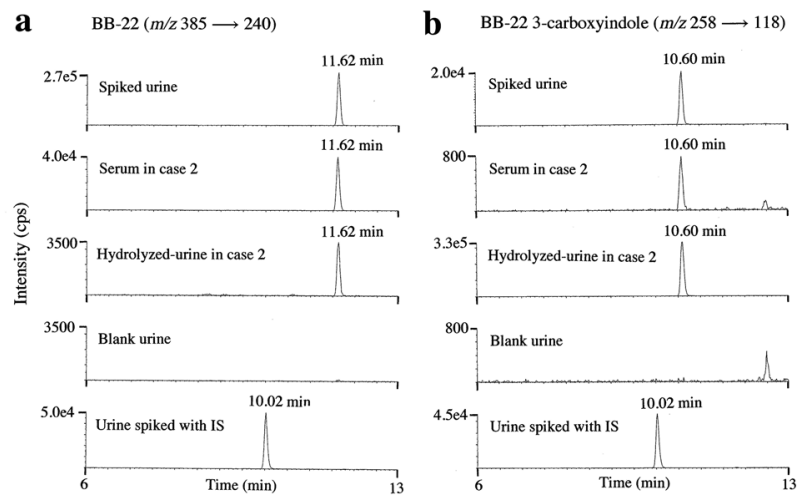

Fig. 2 Selected reaction monitoring (SRM) chromatograms by liquid chromatography (LC)-QTRAP tandem mass spectrometry (MS/ MS) for the detection of BB-22 (a), where the extracts from blank urine spiked with the reference standard at $1.0 \mathrm{ng} / \mathrm{mL}$, the serum in case 2 , the $\beta$-glucuronide-hydrolyzed urine in case 2 , the blank urine and the blank urine spiked with the internal standard (IS) at $1.0 \mathrm{ng} /$ $\mathrm{mL}$ are shown from the top to the bottom panel. The equivalent SRM chromatograms for the detection of BB-22 3-carboxyindole (b) for the blank urine spiked with the reference standard at $10 \mathrm{ng} / \mathrm{mL}$, the serum in case 2 , the hydrolyzed urine in case 2 , the blank urine and the blank urine spiked with the IS at $1.0 \mathrm{ng} / \mathrm{mL}$ are shown. The collision energies for BB-22 and its 3-arboxyindole were 21 and $29 \mathrm{eV}$, respectively 
a $\quad$ BB-22

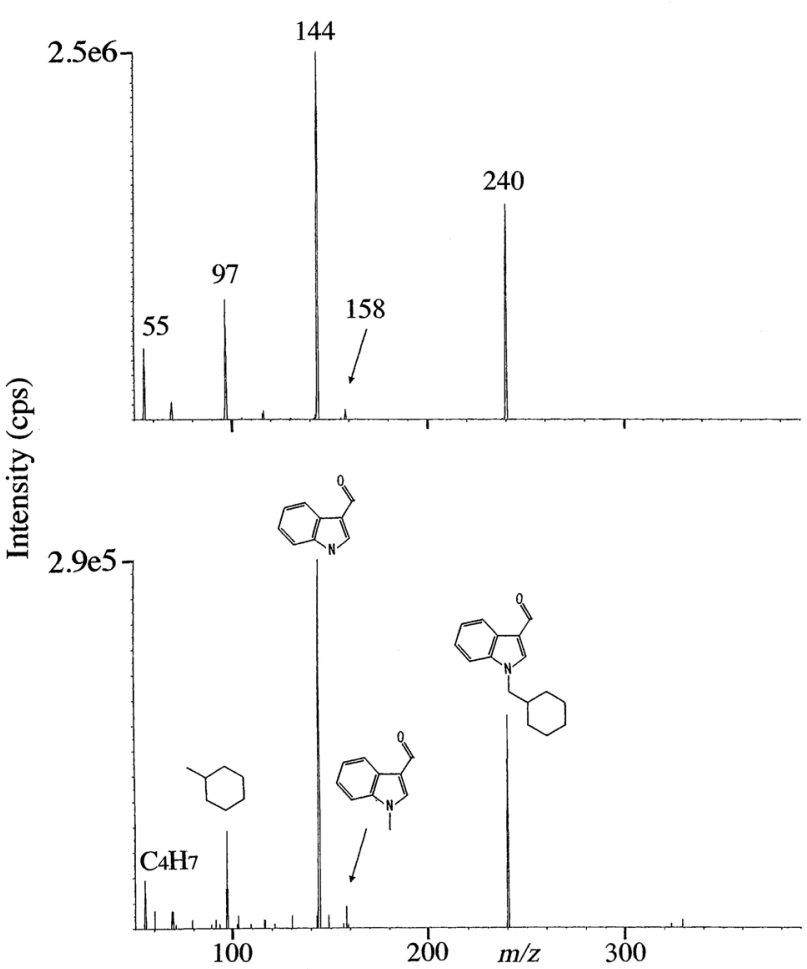

b BB-22 3-carboxyindole
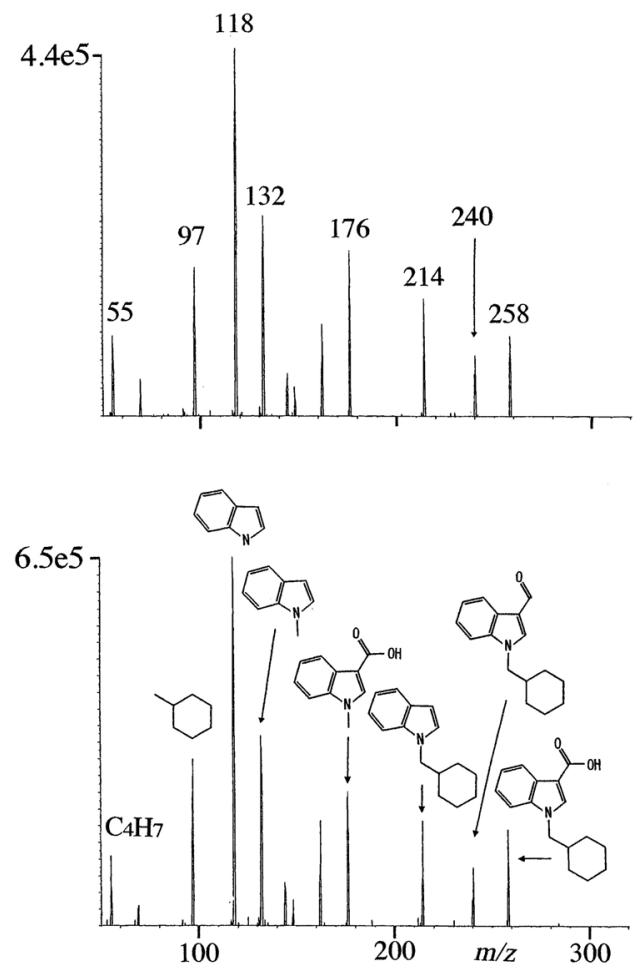

Fig. 3 Product ion spectra for the detection of BB-22 (a), where the reference standard at $10 \mathrm{ng} / \mathrm{mL}$ in methanol is shown in the upper panel and the extract from serum in case 2 in the lower panel. Product ion spectra for BB-22 3-carboxyindole (b), where the reference

Figure $3 \mathrm{a}$ shows the product ion spectrum obtained from the reference standard of BB-22 at $10 \mathrm{ng} / \mathrm{mL}$ in methanol in the upper panel and that from the serum in case 2 in the lower panel for unequivocal identification, where the collision energy at $51 \mathrm{eV}$ was adopted in the detection because the collision energy at $21 \mathrm{eV}$, though suitable for quantification, did not give the enough numbers of qualifier ions. Figure $3 \mathrm{~b}$ shows the equivalent product ion spectrum obtained from the reference standard of standard at $100 \mathrm{ng} / \mathrm{mL}$ in methanol is shown in the upper panel and the extract from hydrolyzed urine in case 2 in the lower panel. The collision energies for BB-22 and its 3-arboxyindole metabolite were 51 and $29 \mathrm{eV}$, respectively

BB-22 3-carboxyindole at $100 \mathrm{ng} / \mathrm{mL}$ in methanol and that from hydrolyzed urine in case 2, except for the collision energy at $29 \mathrm{eV}$ used.

The relative peak height ratios of principal product ions (signal-to-noise ratio $>3$ ) derived from the respective reference standard protonated molecular ions and those from serum and urine samples are listed in Table 1 by taking the highest product ions to be 100 . The ratios of the reference standard of BB-22 and BB-22 3-carboxyindole and those of
Table 1 Relative intensities of the product ions of BB-22 and BB-22 3-carboxyindole derived from the reference standard solutions and from serum and urine in case 2

\begin{tabular}{lllllll}
\hline $\begin{array}{l}\text { Compound (collision energy) and } \\
\text { sample }\end{array}$ & $\begin{array}{l}\text { Protonated molecular } \\
\text { ion }(\mathrm{m} / \mathrm{z})\end{array}$ & \multicolumn{5}{l}{$\begin{array}{l}\text { Product ion }(\mathrm{m} / \mathrm{z}) \\
\text { Percent product ion intensity }\end{array}$} \\
\hline BB-22 $(51 \mathrm{eV})$ & $(385.2)$ & $(144.1)$ & $(240.1)$ & $(97.1)$ & $(55.0)$ & \\
RS $(10 \mathrm{ng} / \mathrm{mL})$ & & 100 & 58.1 & 31.7 & 19.0 & \\
Serum in case 2 & & 100 & 57.8 & 26.8 & 13.4 & \\
Tenfold concentrated urine in case 2 & & 100 & 53.6 & 33.9 & 19.6 & \\
BB-22 3-carboxyindole $(29 \mathrm{eV})$ & $(258.1)$ & $(118.1)$ & $(132.1)$ & $(97.1)$ & $(176.1)$ & $(214.1)$ \\
RS $(100 \mathrm{ng} / \mathrm{mL})$ & & 100 & 51.8 & 45.1 & 36.6 & 28.1 \\
Serum in case 2 & & 100 & 53.1 & 43.8 & 42.1 & 27.7 \\
Hydrolyzed urine in case 2 & & 100 & 53.5 & 40.1 & 45.8 & 31.7 \\
\hline
\end{tabular}

$R S$ reference standard 
serum and urine samples almost agreed with one another, confirming that the peaks from the samples in Fig. 2 were due to the target compounds.

\section{Validation of the method}

The validation experiments were performed using the unhydrolyzed samples, because these compounds were stable during $\beta$-glucuronidase hydrolysis, as mentioned in the previous report on 5F-PB-22 having ester linkage [5].

The linearity of BB-22 using the present method was examined by spiking the compound (at 0, 10, 20, 60, 200 or $2000 \mathrm{pg} / \mathrm{mL}$ in serum and at $0,5,10,30,100$ or $1000 \mathrm{pg} / \mathrm{mL}$ in urine) to blank matrices $(n=6$ at each concentration). The linearity of BB-22 3-carboxyindole was examined by spiking the compound (at $0,0.2,0.6$, 2 or $20 \mathrm{ng} / \mathrm{mL}$ in serum and at $0,0.1,0.3,1$ or $10 \mathrm{ng} /$ $\mathrm{mL}$ in urine, $n=6 \mathrm{each})$. The regression equations for the calibration curves are listed in Table 2, where the correlation coefficients were $0.990-0.999$. The limits of detection (signal-to-noise ratio $=3$ ) of BB-22 and BB-22 3-carboxyindole were 3 and $30 \mathrm{pg} / \mathrm{mL}$ in urine, and 6 and $60 \mathrm{pg} /$ $\mathrm{mL}$ in serum, respectively.

The precisions and the accuracies were assessed by analyzing samples spiked with BB-22 at 10, 20, 60, 200 and $2000 \mathrm{pg} / \mathrm{mL}$ in serum and at 5, 10, 30, 100 and $1000 \mathrm{pg} / \mathrm{mL}$ in urine, respectively, three times a day as well as on three different days. In the determination of precisions and the accuracies of BB-22 3-carboxyindole, samples were spiked with it at $0.2,0.6,2$ and $20 \mathrm{ng} / \mathrm{mL}$ in serum and at $0.1,0.3$, 1 and $10 \mathrm{ng} / \mathrm{mL}$ in urine, respectively. The accuracy data were $82.6-124 \%$ and the precision data were not greater than $28.3 \%$ for intraday and interday measurements as listed in Table 3. These data could be considered to be generally within the acceptable range for the quantification.

The extraction recovery and the matrix effect were calculated according to the method described $[5,6]$. The recoveries in the quantification ranges were 56.7-105\% $(n=3$ at each concentration) and the matrix effects were $75.0-108 \%$

\section{Quantification of unchanged BB-22 and BB-22 3-carboxyindole in authentic serum and urine specimens}

Samples were diluted with blank matrices when the levels of target compounds were out of quantification range. The levels of BB-22 and BB-22 3-carboxyindole in unhydrolyzed serum, those in $\beta$-glucuronide-hydrolyzed serum, those in unhydrolyzed urine and those in hydrolyzed urine were measured ( $n=3$ each), and the results are summarized in Table 4, where the increment of the compound by hydrolysis could be estimated roughly as the concentration of its glucuronidated form. The levels of BB-22 3-carboxyindole in urine increased to 1.7-118 times after the hydrolysis.

The urine levels of BB-22 of abusers have not been reported before. As listed in Table 4, the urine levels of BB-22 were determined to be 5.64, 5.52 and $6.92 \mathrm{pg} / \mathrm{mL}$ in the present cases 1, 2 and 3, respectively. Other SCs in urine were also detected previously by us with pg levels of this order. That is, the levels of six SCs were 10-232 pg/mL in [6], those of 5F-PB-22 of four abusers were $5.1-470 \mathrm{pg}$ / $\mathrm{mL}$ in [7] and those of 5F-NNEI of two abusers were 5.1 and $7.9 \mathrm{pg} / \mathrm{mL}$ in [8].

In the present cases 1 and 2, serum and urine specimens were collected at nearly the same time. The relative ratios of BB-22 levels in urine to those in serum were calculated to be 0.032 in case 1 and 0.00096 in case 2 , respectively, as shown in Table 4, indicating that much more sensitive detection is required for the quantification of $\mathrm{SCs}$ in urine than in serum.

The levels of BB-22 3-carboxyindole as the metabolite of BB-22 in human specimens also have not been reported before. The relative ratios of BB-22 3-carboxyindole levels in serum to BB-22 levels in serum were calculated to be 3.5 in case 1 and 7.6 in case 2, respectively, as shown in Table 4, indicating that the metabolite is the main component even in serum in these cases.

Table 2 Regression equations, correlation coefficients and limits of detection of BB-22 and BB-22 3-carboxyindole spiked into blank serum and urine detected by liquid chromatography-tandem mass spectrometry

\begin{tabular}{lllcc}
\hline Compound & Range & Equation & $\begin{array}{l}\text { Correlation coef- } \\
\text { ficient }\end{array}$ & $\begin{array}{l}\text { Limit of } \\
\text { detection }(\mathrm{pg} / \\
\mathrm{mL})\end{array}$ \\
\hline BB-22 in serum & $10-2000 \mathrm{pg} / \mathrm{mL}$ & $y=0.00543 x+0.0096$ & 0.997 & 6 \\
BB-22 in urine & $5-1000 \mathrm{pg} / \mathrm{mL}$ & $y=0.00647 x+0.0112$ & 0.990 & 3 \\
BB-22 3-carboxyindole in serum & $0.2-20 \mathrm{ng} / \mathrm{mL}$ & $y=0.000226 x+0.00107$ & 0.999 & 60 \\
BB-22 3-carboxyindole in urine & $0.1-10 \mathrm{ng} / \mathrm{mL}$ & $y=0.000240 x+0.000965$ & 0.997 & 30 \\
\hline
\end{tabular}

( $n=3$ at each concentration) as listed in Table 3, which is acceptable for quantitative analysis. 
Table 3 Intraday and interday accuracy/precision, recovery and matrix effect data of BB-22 and BB-22 3-carboxyindole spiked into blank serum and urine $(n=3$ each)
Table 4 Quantifications of BB-22 (pg/mL) and BB-22 3-carboxyindole $(\mathrm{ng} / \mathrm{mL})$ in unhydrolyzed and hydrolyzed serum and/ or urine, and their increments by hydrolysis (i.e., glucuronide compounds) for three cases, respectively

\begin{tabular}{|c|c|c|c|c|c|c|}
\hline \multirow{2}{*}{$\begin{array}{l}\text { Concentra- } \\
\text { tion spiked }\end{array}$} & \multicolumn{2}{|l|}{ Intraday } & \multicolumn{2}{|l|}{ Interday $^{\mathrm{a}}$} & \multirow[t]{2}{*}{ Recovery (\%) } & \multirow{2}{*}{$\begin{array}{l}\text { Matrix } \\
\text { effect } \\
(\%)\end{array}$} \\
\hline & Accuracy $(\%)$ & Precision $(\%)$ & Accuracy $(\%)$ & Precision $(\%)$ & & \\
\hline \multicolumn{7}{|c|}{ BB-22 in serum $(\mathrm{pg} / \mathrm{mL})$} \\
\hline 10 & 104 & 21.1 & 114 & 14.7 & 75.1 & 87.6 \\
\hline 20 & 89.5 & 9.5 & 95.7 & 8.3 & 71.1 & 75.0 \\
\hline 60 & 96.3 & 2.6 & 102 & 3.9 & 56.7 & 81.2 \\
\hline 200 & 105 & 3.6 & 109 & 11.1 & 76.1 & 94.4 \\
\hline 2000 & 102 & 2.8 & 109 & 13.2 & 72.2 & 94.7 \\
\hline \multicolumn{7}{|c|}{ BB-22 in urine $(\mathrm{pg} / \mathrm{mL})$} \\
\hline 5 & 99.0 & 20.2 & 93.0 & 8.4 & 77.9 & 108 \\
\hline 10 & 117 & 7.7 & 106 & 9.1 & 105 & 82.4 \\
\hline 30 & 94.4 & 4.3 & 91.0 & 1.6 & 101 & 80.4 \\
\hline 100 & 111 & 12.2 & 115 & 15.6 & 99.8 & 80.0 \\
\hline 1000 & 110 & 8.4 & 107 & 16.5 & 82.4 & 94.7 \\
\hline \multicolumn{7}{|c|}{ BB-22 3-carboxyindole in serum $(\mathrm{ng} / \mathrm{mL})$} \\
\hline 0.2 & 100 & 14.6 & 100 & 7.5 & 81.0 & 82.6 \\
\hline 0.6 & 101 & 13.9 & 94.4 & 13.6 & 56.9 & 102 \\
\hline 2 & 104 & 0.9 & 100 & 5.7 & 105 & 106 \\
\hline 20 & 97.1 & 3.2 & 101 & 3.4 & 69.2 & 98.2 \\
\hline \multicolumn{7}{|c|}{ PB-22 3-carboxyindole in urine $(\mathrm{ng} / \mathrm{mL})$} \\
\hline 0.1 & 114 & 28.3 & 124 & 18.7 & 103 & 87.1 \\
\hline 0.3 & 103 & 26.3 & 102 & 2.7 & 81.7 & 107 \\
\hline 1 & 82.6 & 7.3 & 95.6 & 9.7 & 75.0 & 95.0 \\
\hline 10 & 100 & 6.8 & 104 & 0.8 & 80.9 & 101 \\
\hline
\end{tabular}

${ }^{\mathrm{a}}$ The interday experiment was made with triplicate determinations $\times 3$ days

\begin{tabular}{|c|c|c|c|}
\hline \multirow[t]{2}{*}{ Case } & \multicolumn{3}{|l|}{ Concentration } \\
\hline & 1 & 2 & 3 \\
\hline \multicolumn{4}{|l|}{ BB-22 in serum $(\mathrm{pg} / \mathrm{mL})$} \\
\hline Unhydrolyzed serum & $149 \pm 16$ & $6680 \pm 420$ & $-{ }^{\mathrm{a}}$ \\
\hline Hydrolyzed serum & $192 \pm 14$ & $6110 \pm 780$ & $-{ }^{\mathrm{a}}$ \\
\hline \multicolumn{4}{|l|}{ BB-22 in urine $(\mathrm{pg} / \mathrm{mL})$} \\
\hline Unhydrolyzed urine & $5.64 \pm 0.36$ & $5.52 \pm 0.50$ & $6.92 \pm 0.42$ \\
\hline Hydrolyzed urine & $6.22 \pm 1.18$ & $5.86 \pm 0.98$ & $7.14 \pm 0.76$ \\
\hline \multicolumn{4}{|l|}{ BB-22 3-carboxyindole in serum (ng/mL) } \\
\hline Unhydrolyzed serum & $0.755 \pm 0.134$ & $38.0 \pm 1.1$ & $-{ }^{\mathrm{a}}$ \\
\hline Hydrolyzed serum & $0.679 \pm 0.110$ & $46.2 \pm 1.8$ & $-{ }^{\mathrm{a}}$ \\
\hline \multicolumn{4}{|l|}{ BB-22 3-carboxyindole in urine $(\mathrm{ng} / \mathrm{mL})$} \\
\hline Unhydrolyzed urine & $0.131 \pm 0.033$ & $21.4 \pm 1.6$ & $5.15 \pm 0.24$ \\
\hline Hydrolyzed urine & $0.217 \pm 0.014$ & $765 \pm 87$ & $606 \pm 11$ \\
\hline $\begin{array}{l}\text { Ratio of BB-22 3-carboxyindole in hydrolyzed } \\
\text { urine to that in unhydrolyzed urine }\end{array}$ & 1.65 & 35.7 & 118 \\
\hline
\end{tabular}

Each concentration value is the mean \pm standard deviation (SD) obtained from triplicate determinations

${ }^{\text {a }}$ Sample was unavailable

\section{Characterization of metabolites of BB-22 other than BB-22 3-carboxyindole in authentic urine specimens in cases 2 and 3}

Because the reference standards for metabolites of BB-22 other than BB-22 3-carboxyindole were not available, they could be identified only tentatively on the basis of high-resolution MS. As can be seen in Table 5, the positive protonated 
Table 5 Accurate mass data, elemental composition, precursor ion in $m / z$ with its mass error in parenthesis (ppm), diagnostic product ions in $m / z$ with their mass errors in parentheses (ppm) for metabolites M1-M4' in two cases

\begin{tabular}{llll}
\hline Metabolites & $\begin{array}{l}\text { Elemental } \\
\text { composition }\end{array}$ & $\begin{array}{l}\text { Precursor ion in } \\
m / z \text { observed } \\
(\text { mass error, ppm) }\end{array}$ & Diagnostic product ions in $m / z$ observed (mass errors, ppm) \\
\hline M1 & $\mathrm{C}_{25} \mathrm{H}_{25} \mathrm{~N}_{2} \mathrm{O}_{3}$ & $401.1866(-1.3)$ & $256.1340(+3.1), 158.0605(+3.2), 144.0443(0), 130.0657(+4.6), 95.0863(+8.4)$ \\
$\mathrm{M} 2$ & $\mathrm{C}_{25} \mathrm{H}_{25} \mathrm{~N}_{2} \mathrm{O}_{3}$ & $401.1867(+2.0)$ & $256.1337(+2.0), 160.0399(+3.7), 97.1019(+8.2), 55.0552(+9.1)$ \\
M3,3' & $\mathrm{C}_{16} \mathrm{H}_{20} \mathrm{NO}_{3}$ & $274.1442(+1.8)$ & $256.1328(-6.6), 212.1436(+1.4), 174.0556(+4.0), 130.0653(+1.5), 118.0653(+5.9)$, \\
& & $95.0859(+4.2)$ & \\
M4,4' & $\mathrm{C}_{16} \mathrm{H}_{20} \mathrm{NO}_{3}$ & $274.1438(+0.4)$ & $\begin{array}{c}256.1334(+0.8), 230.1535(-1.7), 192.0659(+2.1), 148.0760(+2.0), 134.0603(+2.2), \\
\end{array}$ \\
\end{tabular}

molecular metabolites could be measured down to the fourth decimal place with errors not greater than $2.0 \mathrm{ppm}$ in many product ions using the high-resolution Orbitrap MS instrument. Both M1 and M2 metabolites were obtained by the ion transition of $m / z \quad 401 \rightarrow 256$, but could be differentiated by different retention times at 10.27 and $10.97 \mathrm{~min}$, respectively (Fig. 4a). They were monohydroxyl metabolites of BB-22 at the cyclohexylmethyl and indole core moieties, respectively (Fig. 1).

Both M3 and M3' were monohydroxyl metabolites formed from BB-22 3-carboxyindole at the cyclohexylmethyl moiety, with different retention times at 7.57 and
$8.10 \mathrm{~min}$, respectively (Fig. 4b). The exact locations of hydroxylation in the cyclohexylmethyl moiety were not known (Fig. 1). Both M4 and M4' were also monohydroxyl metabolites formed from BB-22 3-carboxyindole at the indole core moiety with different retention times at 9.17 and $9.45 \mathrm{~min}$, respectively (Fig. 4c). The exact locations of hydroxylation in the indole core moiety also could not be identified (Fig. 1).

For confirmation of the structures of the above metabolites, their product ion spectra were measured by LC-MS/ MS as shown in Fig. 5. The product ion spectrum of M3 and that of M3' were almost the same; hence they are denoted

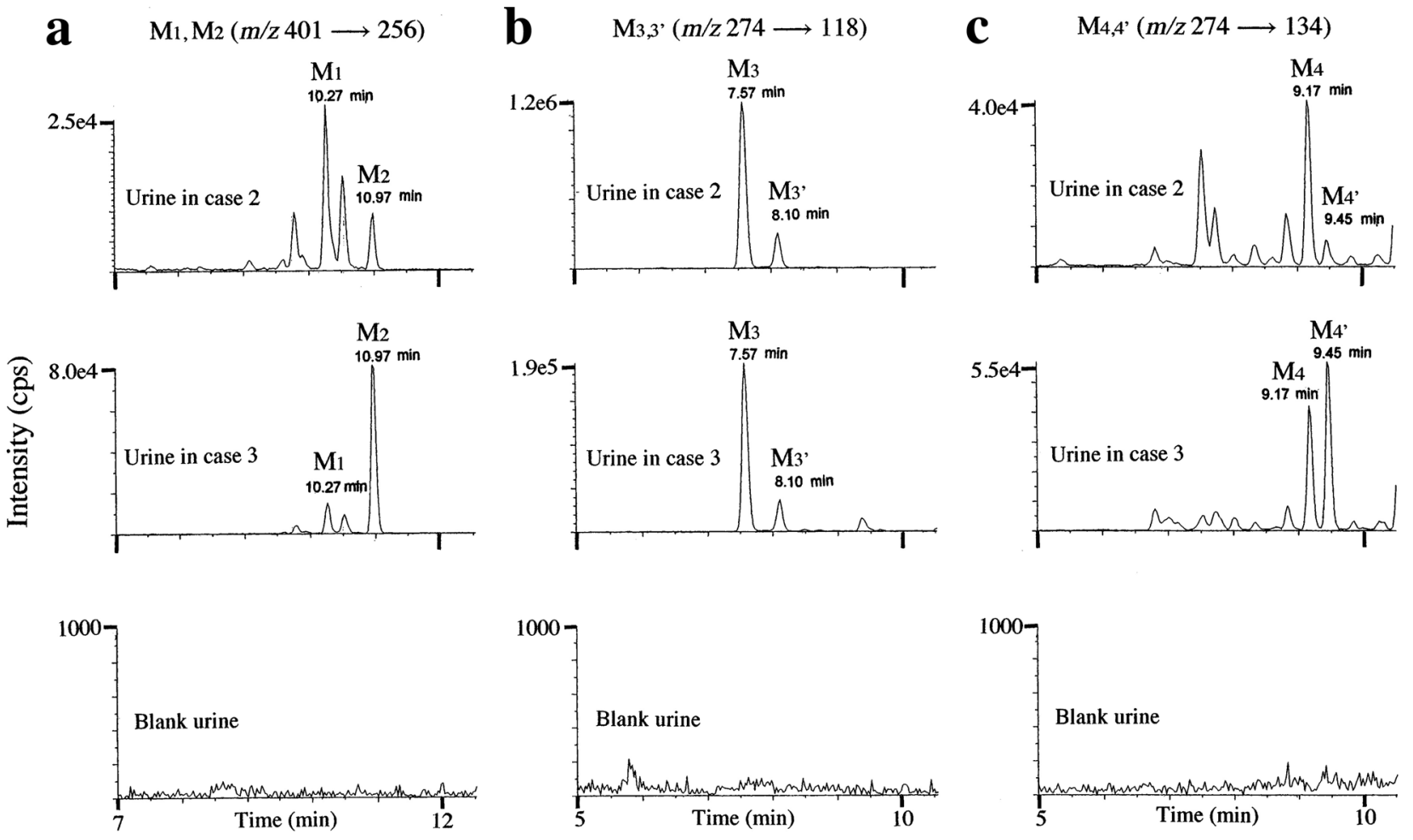

Fig. 4 SRM chromatograms by LC-QTRAP-MS/MS for the detection of M1 and M2 (a), where the extract from hydrolyzed urine in case 2, that in case 3 and that from blank urine are shown from the top to the bottom panel. The equivalent SRM chromatograms are also shown for the detection of M3,3' (b) and M4,4' (c). The collision energies for $\mathbf{a}, \mathbf{b}$ and $\mathbf{c}$ were 21,29 and $29 \mathrm{eV}$, respectively 
Fig. 5 Product ion spectra by LC-MS/MS for the characterization of M1-M4,4', where the extract from hydrolyzed urine in case 3 was used for M1 and M2 with collision energy at $51 \mathrm{eV}$ and that in case 2 was used for M3,3' and M4,4' with collision energy at $29 \mathrm{eV}$

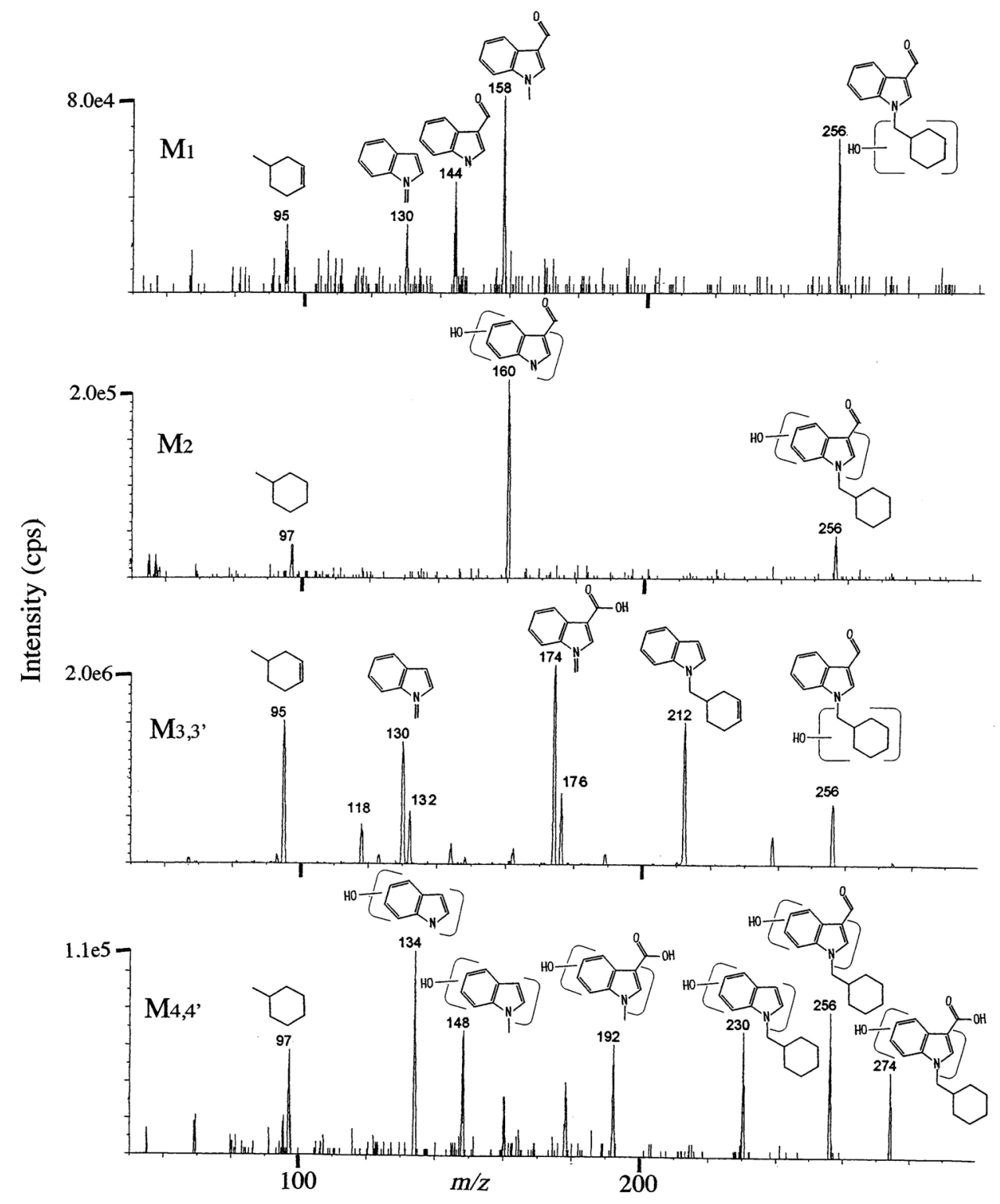

as $\mathrm{M} 3,3^{\prime}$, and for the same reason, the product ion spectrum of M4 and that of M4' are denoted as M4,4'. Based on the elemental compositions of the product ions described in Table 5, the structures of major product ions were estimated as shown in Fig. 5, where only one structure was written for each product ion, although several regioisomers were possible for each product ion. The observed major product ions (Fig. 5) agreed quite well with the theoretical values measured by high-resolution MS as listed in Table 5.

In Fig. 5, all the metabolites M1-M4,4' showed the diagnostic product ion at $\mathrm{m} / \mathrm{z} 256$ indicating that the monohydroxylation (i.e., + 16) occurred at BB-22 3-carboxylindole moiety showing its product ion at $m / z 240$ in Fig. 3a, b.

The product ion of M2 at $m / z 160$ indicated that the monohydroxylation occurred at indole core moiety of BB-22, whereas the product ion at $m / z, 97$ indicated that the cyclohexylmethyl moiety of BB-22 showing its product ion at $m / z 97$ was intact. Therefore, monohydroxylation of M2 occurred at indole moiety.

The product ions of M4,4' at $m / z 230,192,148$ and 134 were monohydroxylated ones of the ions at $m / z 214,176$, 132 and 118, respectively, which were observed as the product ions of BB-22 3-carboxyindole in Fig. 3b, whereas the product ion of $\mathrm{M} 4,4^{\prime}$ at $\mathrm{m} / \mathrm{z} 97$ indicated that its cyclohexylmethyl moiety was intact. Therefore, the monohydroxylation of M4,4' occurred at indole moiety.

On the other hand, the product ion of M1 at $\mathrm{m} / \mathrm{z} 95 \mathrm{sug}-$ gested that the monohydroxylation occurred at cyclohexylmethyl moiety and then dehydration occurred there. The product ions of M1 at $\mathrm{m} / \mathrm{z} 158$ and 144 were the same product ions of BB-22 as observed in Fig. 3a, indicating that indole core moiety was not hydroxylated. The product 
ion of M1 at $\mathrm{m} / z, 130$ is considered to be the dehydrogenated ion of BB-22 3-carboxyindole at $\mathrm{m} / \mathrm{z}, 132$, which is observable when hydroxylation-dehydration has occurred. Therefore, the monohydroxylation of M1 occurred at the cycohexylmethyl moiety.

The product ion of M3, $3^{\prime}$ at $m / z, 95$ indicated that the hydroxylation occurred at cyclohexylmethyl moiety and then dehydration occurred. The product ions of M3,3' at $\mathrm{m} / \mathrm{z}, 176,132$ and 118 were the same product ions of BB-22 3 -carboxyindole as observed in Fig. 3b, indicating that indole moiety was not hydroxylated. The product ions of M3,3' at $m / z, 212,174$ and 130 were the dehydrogenated ions of BB-22 3-carboxyindole at $\mathrm{m} / \mathrm{z} 214,176$ and 132, respectively, which is observable when hydroxylationdehydration occurred. Therefore, the monohydroxylation of M3,3' occurred at cyclohexylmethyl moiety.

In this way, the monohydroxylation at indole moiety and that at cyclohexylmethyl moiety of BB-22 as well as BB-22 3-carboxylindole have been clearly distinguished, although other regioisomers seem still to be included in each of the metabolites M1-M4,4'.

Because the quantifications of the metabolites M1-M4' could not be realized, the relative peak height intensity ratios of each of them to the peak height of the IS at $1 \mathrm{ng} /$ $\mathrm{mL}$ are presented in Table 6 . The relative ratios of all the metabolites in the hydrolyzed urine were higher than those in the unhydrolized urine, indicating that they were in their conjugated forms, most probably glucuronidated forms.

Although BB-22 3-carboxyindole, M3,3' and M4,4' were also produced from MDMB-CHMICA and ADBCHMICA [5], M1 and M2 after hydrolysis are specific to BB-22. Therefore, the urinary concentrations of metabolites M1 and M2 after hydrolysis listed in Table 6 should be roughly compared with the urinary concentrations of BB-22 listed in Table 4. The peak height intensity ratio of $1 \mathrm{ng} / \mathrm{mL}$ of M1 or M2 to $1 \mathrm{ng} / \mathrm{mL}$ of IS can be roughly estimated to be 1 considering the structures of M1, M2 and IS. In that assumption, the concentrations of M1 and M2 will be 240 and $79 \mathrm{pg} / \mathrm{mL}$ in case 2, and those will be 200 and $1200 \mathrm{pg} / \mathrm{mL}$ in case 3, respectively. Therefore, the concentrations of M1 and M2 are calculated to be 41 and 13-fold higher than that of BB-22 in case 2, and 28 and 170-fold higher than that of BB-22 in case 3, respectively. This means that the detection of M1 and M2 in urine is easier than the detection of BB-22.

Very recently, Carlier et al. [5] have reported the in vitro metabolism of BB-22 by human hepatocytes. Although they have tentatively identified 10 metabolites, they did not include the M1 and M2 metabolites found in this in vivo study. The in vitro metabolites from the BB-22 3 carboxyindole were in common with those found in this study. It should be kept in mind that the metabolic pathways found in the in vitro experiments are not exactly the same as those
Table 6 Relative intensities of metabolites M1-M4' calculated as the ratio of its peak height to the peak height of the internal standard at $1 \mathrm{ng} / \mathrm{mL}$ in unhydrolyzed and hydrolyzed urine in two cases

\begin{tabular}{|c|c|c|c|}
\hline Metabolite & Case & 2 & 3 \\
\hline \multirow[t]{2}{*}{ M1 } & $\begin{array}{l}\text { Unhydrolyzed } \\
\text { urine }\end{array}$ & $0.00171 \pm 0.00027$ & $0.00073 \pm 0.00012$ \\
\hline & $\begin{array}{l}\text { Hydrolyzed } \\
\text { urine }\end{array}$ & $0.242 \pm 0.015$ & $0.203 \pm 0.022$ \\
\hline \multirow[t]{2}{*}{ M2 } & $\begin{array}{l}\text { Unhydrolyzed } \\
\text { urine }\end{array}$ & $0.00099 \pm 0.00016$ & $0.00454 \pm 0.00080$ \\
\hline & $\begin{array}{l}\text { Hydrolyzed } \\
\text { urine }\end{array}$ & $0.0787 \pm 0.0042$ & $1.20 \pm 0.11$ \\
\hline \multirow[t]{2}{*}{ M3 } & $\begin{array}{l}\text { Unhydrolyzed } \\
\text { urine }\end{array}$ & $1.050 \pm 0.050$ & $0.00727 \pm 0.00074$ \\
\hline & $\begin{array}{l}\text { Hydrolyzed } \\
\text { urine }\end{array}$ & $12.4 \pm 1.1$ & $2.31 \pm 0.16$ \\
\hline \multirow[t]{2}{*}{ M3' } & $\begin{array}{l}\text { Unhydrolyzed } \\
\text { urine }\end{array}$ & $0.209 \pm 0.022$ & $0.00089 \pm 0.00024$ \\
\hline & $\begin{array}{l}\text { Hydrolyzed } \\
\text { urine }\end{array}$ & $2.16 \pm 0.080$ & $0.43 \pm 0.065$ \\
\hline \multirow[t]{2}{*}{ M4 } & $\begin{array}{l}\text { Unhydrolyzed } \\
\text { urine }\end{array}$ & $0.0204 \pm 0.0020$ & $0.0013 \pm 0.00045$ \\
\hline & $\begin{array}{l}\text { Hydrolyzed } \\
\text { urine }\end{array}$ & $0.0320 \pm 0.076$ & $0.525 \pm 0.019$ \\
\hline \multirow[t]{2}{*}{ M4' } & $\begin{array}{l}\text { Unhydrolyzed } \\
\text { urine }\end{array}$ & $0.00207 \pm 0.00025$ & $0.00243 \pm 0.00053$ \\
\hline & $\begin{array}{l}\text { Hydrolyzed } \\
\text { urine }\end{array}$ & $0.0520 \pm 0.0069$ & $0.718 \pm 0.022$ \\
\hline
\end{tabular}

Each value is the mean $\pm \mathrm{SD}$ obtained from triplicate determinations

found in urine specimens of drug users, despite that the in vitro hepatocytes are of human origin.

\section{Conclusions}

To our knowledge, this is the first report to quantify BB-22 and BB-22 3-carboxyindole in authentic human urine specimens from three individuals. Furthermore, metabolites of BB-22 after hydroxylation (M1 and M2) and ester hydrolysis with hydroxylation (M3,3' and M4,4') have been characterized in urine specimens of two individuals for the first time by high-resolution-MS/MS and QTRAP-MS/MS.

Acknowledgements This work was supported by JSPS KAKENHI Grant Number JP16K09206.

\section{Compliance with ethical standards}

Conflict of interest There are no financial or other relations that could lead to a conflict of interest.

Ethical approval All procedures performed in this study involving human participants were in accordance with the ethical standards of the international and/or national committee and with the 1964 Declaration 
of Helsinki and its later amendments or comparable ethical standards. Informed consent was obtained from all participants included in the study, who supplied about $10 \mathrm{~mL}$ each of blood and/or $40 \mathrm{~mL}$ each of urine for use as blank samples. The analyses of toxic substances from patients presenting to emergency department of the hospital and the individual who was suspected by the police having used illegal drugs were permitted by judicial authorities and supported by official documentation.

Open Access This article is distributed under the terms of the Creative Commons Attribution 4.0 International License (http://creativeco mmons.org/licenses/by/4.0/), which permits unrestricted use, distribution, and reproduction in any medium, provided you give appropriate credit to the original author(s) and the source, provide a link to the Creative Commons license, and indicate if changes were made.

\section{References}

1. Uchiyama N, Matsuda S, Kawamura M, Kikura-Hanajiri R, Goda Y (2013) Two new-type cannabimimetic quinolinyl carboxylates, QUPIC and QUCHIC, two new cannabimimetic carboxamide derivatives, ADB-FUBINACA and ADBICA, and five synthetic cannabinoids detected with a thiophene derivative $\alpha$-PVT and an opioid receptor agonist AH-7921 identified in illegal products. Forensic Toxicol 31:223-240

2. De Luca MA, Castelli MP, Loi B, Porcu A, Martorelli M, Miliano C, Kellett K, Davidson C, Stair JL, Schifano F, Di Chiara G (2016) Native CB1 receptor affinity, intrinsic activity and accumbens shell dopamine stimulant properties of third generation SPICE/
K2 cannabinoids: BB-22, 5F-PB-22, 5F-AKB-48 and STS- 135. Neuropharmacology 105:630-638

3. Schep LJ, Slaughter RJ, Hudson S, Place R, Watts M (2015) Delayed seizure-like activity following analytically confirmed use of previously unreported synthetic cannabinoid analogues. Hum Exp Toxicol 34:557-560

4. Thomsen R, Nielsen LM, Holm NB, Rasmussen HB, Linnet K, the INDICES Consortium (2015) Synthetic cannabimimetic agents metabolized by carboxylesterases. Drug Test Anal 7:565-576

5. Carlier J, Diao X, Huestis MA (2018) Synthetic cannabinoid BB-22 (QUCHIC): human hepatocytes metabolism with liquid chromatography-high resolution mass spectrometry detection. J Pharm Biomed Anal 157:27-35

6. Minakata K, Yamagishi I, Nozawa H, Hasegawa K, Suzuki M, Gonmori K, Suzuki O, Watanabe K (2017) Sensitive identification and quantitation of parent forms of six synthetic cannabinoids in urine samples of human cadavers by liquid chromatography-tandem mass spectrometry. Forensic Toxicol 35:275-283

7. Minakata K, Hasegawa K, Yamagishi I, Nozawa H, KikuraHanajiri R, Suzuki M, Kitamoto T, Suzuki O, Watanabe K (2018) Sensitive quantification of 5F-PB-22 and its three metabolites 5F-PB-22 3-carboxyindole, PB-22 N-5-hydroxypentyl and PB-22 $\mathrm{N}$-pentanoic acid in authentic urine specimens obtained from four individuals by liquid chromatography-tandem mass spectrometry. Forensic Toxicol 36:151-159

8. Minakata K, Nozawa H, Yamagishi I, Hasegawa K, Saitoh T, Yoshino A, Suzuki M, Kitamoto T, Suzuki O, Watanabe K (2018) Sensitive quantification of 5F-NNEI and characterization of its several metabolites in authentic urine and/or serum specimens obtained from three individuals by LC-QTRAP-MS/MS and highresolution LC-Orbitrap-MS/MS. Forensic Toxicol 36:498-505 